\title{
Fabrication and Study of Memory Cell Switching Properties Based on $\mathrm{Cu}_{2} \mathrm{~S}$ Compound
}

\author{
Dr. Khalid Khaleel Mohammad \\ University of Mosul \\ College of Engineering \\ Elect. Eng. Dept.
}

\section{Faris Hassan Taha}

\begin{abstract}
A variety of materials having large non-volatile resistance change has been studied as potential candidates for next generation of non-volatile memory devices, in this device, information is stored as a change in resistance due to the formation of the metallic filament via the reduction of metal ions in the solid electrolyte. Key attributes are low voltage, low current, rapid write and erase, good retention and endurance, and the ability for the storage cells to be physically scaled to a few tens of $\mathrm{nm}$. This paper presents experimental results for solid state devices based on copper sulfide $\left(\mathrm{Cu}_{2} \mathrm{~S}\right) \mathrm{I}-\mathrm{V}$ characteristics.

Keywords: $\mathrm{Cu}_{2} \mathrm{~S}$ memory cell, non-volatile memory

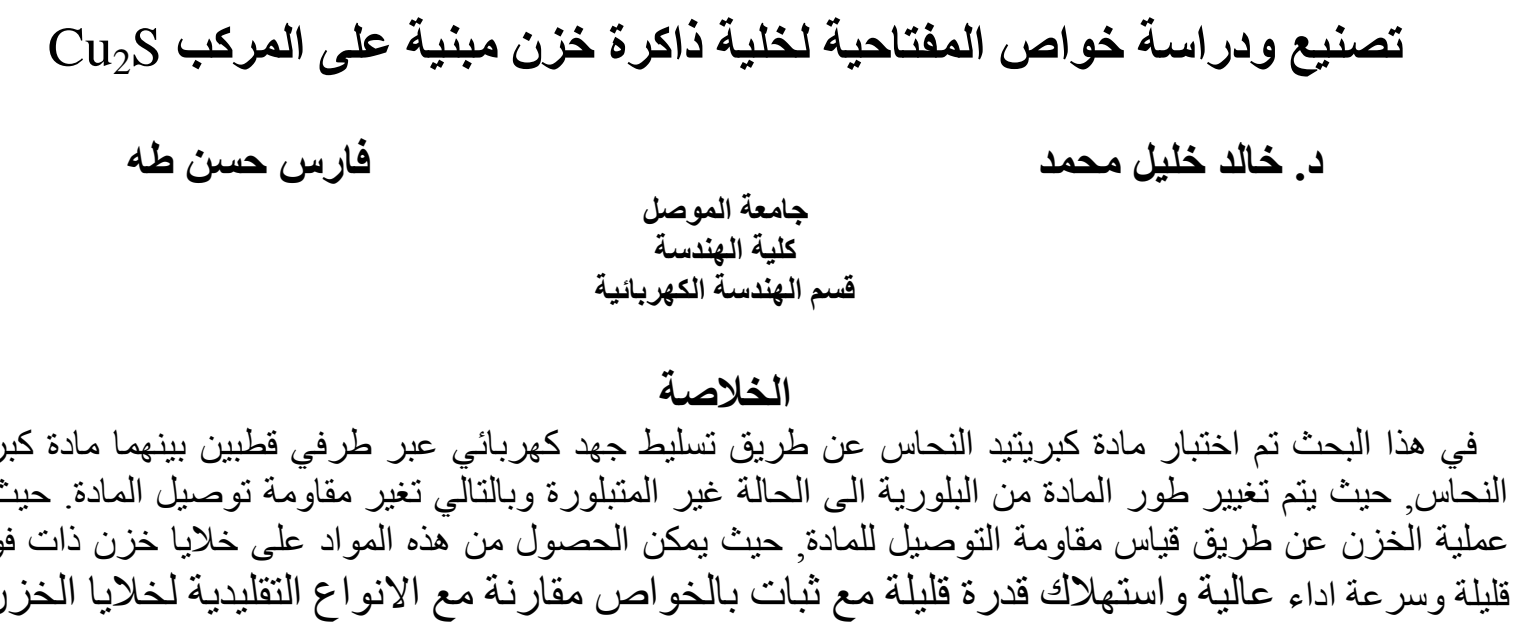

Received: 16 - 8 - 2011

Accepted: 2 - 1 - 2012 


\section{Introduction}

Physical size reduction of memory based on charge storage will result in unacceptable retention or state detection characteristics and the voltage, power, and cost requirements of upcoming memory applications, especially those in portable or "unconnected" systems, make many other approaches to solid state data storage undesirable[1]. Non-volatile memories based on phase transformation, reversible defect generation/recombination, filament and metallic Nano-wire growth/etch are being extensively studied as an alternative to floating gate based flash memory devices currently in use in stick memories and other applications[2]. One of the promising technologies under development for next generation non-volatile memory is the Conductive Bridging Random Access Memory (CBRAM) which utilizes the reversible switching of an electro resistive dielectric between two conductive states as means of storing logical data [3].

Device formation involves the dissolution of silver or copper in a chalcogenide (e.g., germanium selenide, germanium sulfide) or oxide (e.g., tungsten oxide) base glass to create a solid electrolyte. A silver-or copper-containing layer and an inert electrode formed in contact with the electrolyte film creates a device in which information is stored via electrical changes caused by the oxidation of silver or copper metal and reduction of silver or copper ions in the electrolyte[1].

\subsection{Principle of Operation}

Resistance-variable devices, in which a conductive path is formed or annihilated electrochemically, have been proposed by various groups for potential application to nonvolatile memories and switches. In 1976, Hirose et al. reported the first resistive switch, metal ions can migrate and an electronic conducting path is formed or annihilated by applying a positive or negative voltage to the electrode. $\mathrm{Cu}$ is more compatible with current interconnect technology than Ag. The switch is composed of a $\mathrm{Cu}_{2-\alpha} \mathrm{S}$ sandwiched by $\mathrm{Cu}$ and $\mathrm{Pt}$. Applying a positive voltage to the $\mathrm{Cu}$ electrode oxidizes the $\mathrm{Cu}$ metal at the interface between the $\mathrm{Cu}_{2-\alpha} \mathrm{S}$ and $\mathrm{Cu}$ electrode Fig. 1

$\mathrm{Cu} \rightarrow \mathrm{Cu}^{+}+e^{-}$

$\mathrm{Cu}^{+}$ions are dissolved into $\mathrm{Cu}_{2-\alpha} \mathrm{S}$ on the $\mathrm{Cu}$

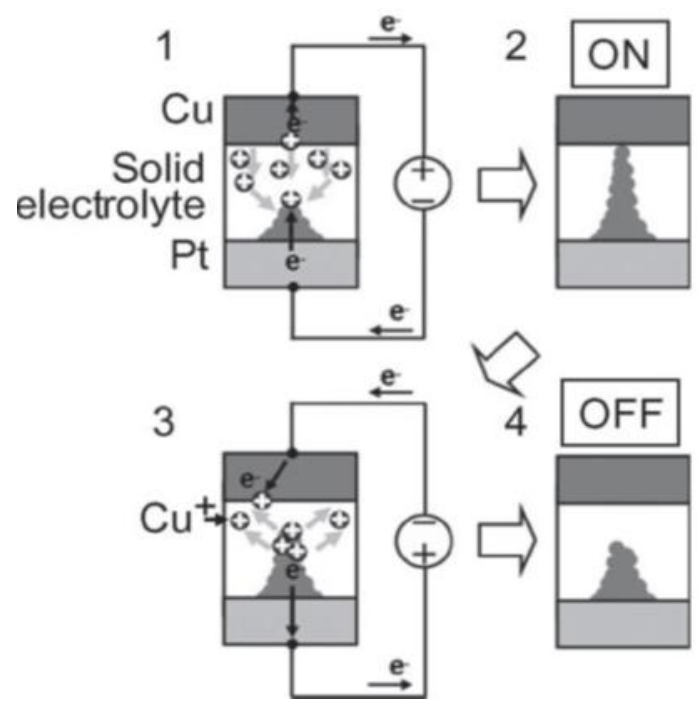

Fig. (1) Schematic view of the operation principle of the solid-electrolyte switch $1.2 \mathrm{ON}$ state $3.4 \mathrm{OFF}$ state.

electrode. On the $\mathrm{Pt}$ electrode, $\mathrm{Cu}+$ ions are reduced and precipitated

$\mathrm{Cu}^{+}+e^{-} \rightarrow \mathrm{Cu}$

The precipitated $\mathrm{Cu}$ grows to form a conducting bridge between the $\mathrm{Pt}$ and $\mathrm{Cu}$ electrodes, and the current flowing between them increases steeply at $0.14 \mathrm{~V}$ as shown in Fig.(1). This puts the switch in the ON state. Subsequently, when a negative voltage is applied to the $\mathrm{Cu}$ electrode, the reverse reactions occur, and the bridge is dissolved into $\mathrm{Cu}_{2-\alpha} \mathrm{S}$. Then, the switch turns off at $-0.11 \mathrm{~V}$ [4]. The characteristic of the switching mechanisms are shown in fig. (2) 
When a positive voltage is applied to the $\mathrm{Cu}$ electrode, a $\mathrm{Cu}$ bridge is formed and the switch is turned on. $\mathrm{Cu}+$ ions are supplied via an electrochemical reaction at the solid-electrolyte/Cu interface. When a negative voltage is applied to the $\mathrm{Pt}$ electrode, the $\mathrm{Cu}$ bridge dissolves into the solidelectrolyte and the switch is turned off. (b) Linear and logarithmic current-voltage curves of $\mathrm{Cu}_{2-\alpha} \mathrm{S}$ switch.

Current $\mathbf{J}$ associated with charged ion $\mathrm{i}$ is given by $J_{i}=-\sigma_{i} \frac{\partial U}{\partial X}$

Where $\sigma \mathrm{i}$ is the conductivity corresponding to different charged particle, The equation (1) essentially is Ohm's Law and the total conductivity $\sigma \mathrm{t}$ then

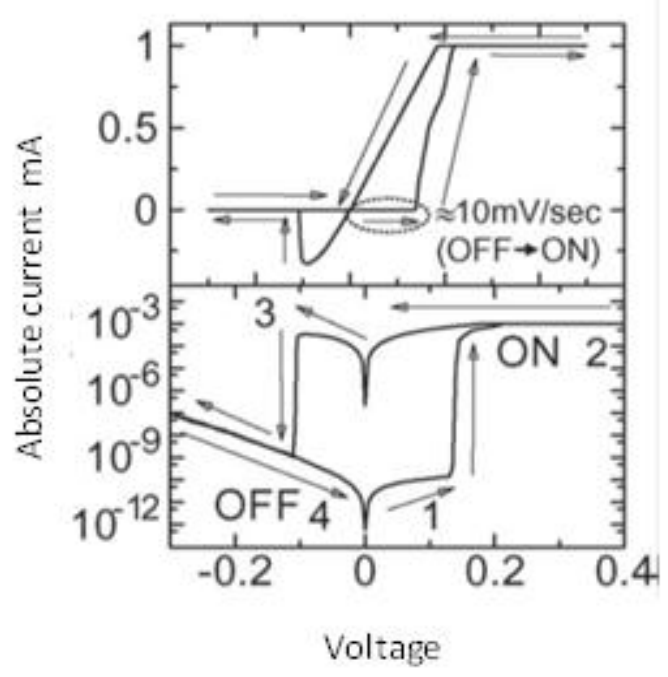

Fig.(2) I-V curve

$\sigma_{t}=\sum_{i} \sigma_{i}=\sigma_{C u^{+}}+\sigma_{C u^{2+}}+\sigma_{S^{2-}}+\sigma_{e}$

The ion conductivity $\left(\sigma_{\text {ion }}\right)$ in $\mathrm{Cu}_{\mathrm{x}} \mathrm{S}$ system thus can be described as $\sigma_{\text {ion }}=C_{\text {ion }} \mu_{\text {ion }} Z_{\text {ion }}^{2} q$

Where $C_{i o n}$ and $\mu_{\text {ion }}$ are ion concentration and mobility respectively,Zion equals to $1 \sim 2$,corresponding to $\mathrm{CuS}, \mathrm{Cu}_{\mathrm{x}} \mathrm{S}$ and $\mathrm{Cu}_{2} \mathrm{~S}$ (x ranges between 1 and 2)[6].

The flux of $\mathrm{Cu}$ in $\mathrm{Cu}_{2} \mathrm{~S}$ is described as [4]

$J_{C u^{+}}=-\frac{D_{C u^{+}}}{R T} \nabla\left(R T \ln a_{C u^{+}}^{C u_{2 S}}+F_{Z C u} \emptyset^{C u_{2 S}}\right)$

where D: is the diffusive coefficient, a: is the activity, factor $\varphi$ : is the electric potential, R: is the gas constant, T: is the temperature, F: is Faraday's constant, and $\mathrm{z}$ : is the valence. Assuming a redox reaction between $\mathrm{Cu}$ and $\mathrm{Cu}$ at the $\mathrm{Cu} / \mathrm{Cu}_{2} \mathrm{~S}$ interface, the flux across an interface with width $\Delta \mathrm{y}$ is defined as

$J_{\text {interface }}=\frac{-M\left\{F_{Z C u} \emptyset^{C u_{-}}\left(R T \ln a_{C u^{+}}^{C u_{2 S}}+F_{Z C u} \emptyset^{C u_{2 S}}\right)-F_{Z C u} E^{\text {excess }}\right\}}{\Delta y}$

where $\mathrm{M}$ is the average of the motilities of $\mathrm{Cu}$ in $\mathrm{Cu}_{2} \mathrm{~S}$. E excess represents the sum of the standard electrode potential and the over potential. In addition, the distribution of the electrical potential is obtained by solving the equation of charge conservation for the entire region (i.e., $\mathrm{Cu}, \mathrm{Cu}_{2} \mathrm{~S}, \mathrm{Pt}$, and the void) simultaneously. The electric currents, are described as[5]

$\nabla . i_{j}=0$

$i_{h}=-\frac{\sigma_{h}}{F_{Z_{h}}} \nabla\left(R T \ln p+F_{Z_{h}} \emptyset\right)$

$i_{e^{-}}=-\sigma_{e^{-}} \nabla \emptyset$

Where $\left(i_{j}\right)$ in $\mathrm{Cu}_{2} \mathrm{~S}$ are regarded as hole conduction and in other regions are regarded as electron conduction.

Where $\sigma$ : is the electric conductivity, and $\mathrm{p}$ : is the hole concentration, defined by the defect chemical equation as

$p=\left(K a_{C u}\right)^{-1 / 2}$

Where $\mathrm{K}$ is the equilibrium constant [5] These features are advantageous in programmable LSI circuits, such as a field programmable gate array (FPGA). An FPGA is composed of reconfigurable logic cells and interconnections that are programmed by a large number of switches [5]. 
A numerical of solution equation (10) [6] of the partial differential equation can be obtained using Matlab to get a copper concentration with varied time and distance as shown in fig. 3

$\frac{\partial C_{i o n}}{\partial t}=D_{i o n} \frac{Z_{i o n} q v}{R T}\left(\frac{\partial C_{i o n}}{\partial x_{\circ}} \frac{1}{L-x_{\circ}} \frac{C_{i o n}}{\left(L-x_{\circ}\right)^{2}}\right)$

\section{Device Fabrication}

Two structure cells were fabricated on glass substrates as shown in fig.(4). The first structure cell was composed of the copper layer with thickness of $2000 \mathrm{~A}^{\circ}$ and $\mathrm{Cu}_{2} \mathrm{~S}$ layer with different thickness $\left(700-1000 \mathrm{~A}^{\circ}\right)$. The inert electrode is fabricated from aluminum metal and gold material for another structure instead of platinum $\mathrm{Pt}$. The second structure is fabricated

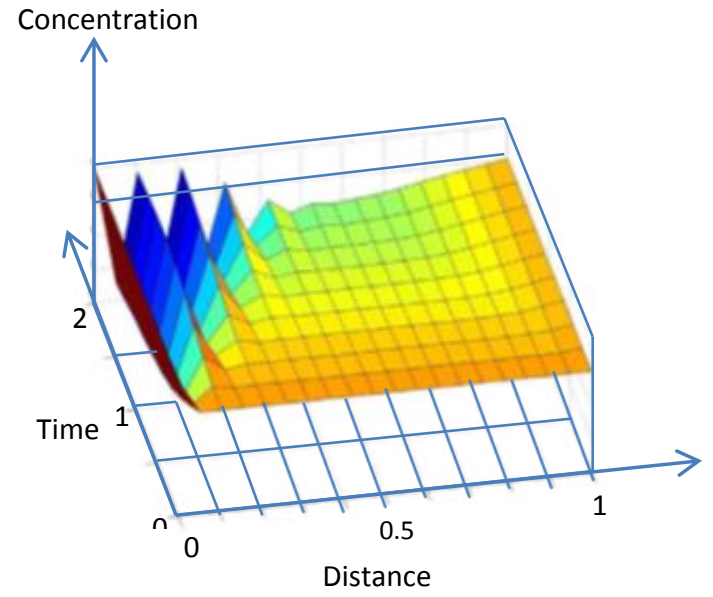

Fig. (3) Numerical simulation of concentration versus distance and time with low voltage and high voltage in a different form as shown in fig.(4b),the $\mathrm{Cu}$ layer thickness is about $2000 \mathrm{~A}^{\circ}$ while the $\mathrm{Cu}_{2} \mathrm{~S}$ layer thickness is about $400 \mathrm{~A}^{\circ}$. The top contact electrode was fabricated from gold material with thickness of about $1000 \mathrm{~A}^{\circ}$.

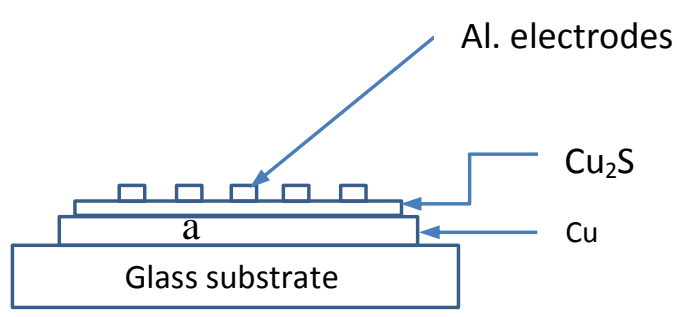

fig. (4) Fabricated $\mathrm{Cu}_{2} \mathrm{~S} / \mathrm{Cu}$ samples structure

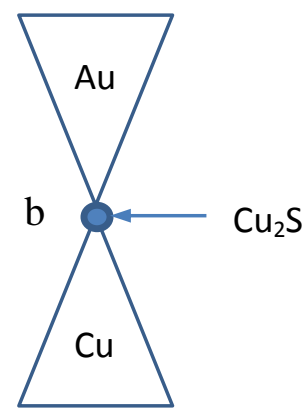

The $\mathrm{Cu}_{2} \mathrm{~S}$ layer of thickness $500 \mathrm{~A}^{\circ}$ is then deposited by evaporating copper and sulphur from two separate tungsten and molybdenum boats. Fig. 5 shows the arrangement for evaporation of copper and sulphur, copper is placed on the tungsten boat which is resistively heated using a low tension power supply. Sulphur is placed on molybdenum boat with a cover and a small opening on top. The sulphur source is placed at a distance of about $3 \mathrm{~cm}$ above the copper source. When the copper source is heated it also indirectly heats the boat containing sulphur and the simultaneous evaporation

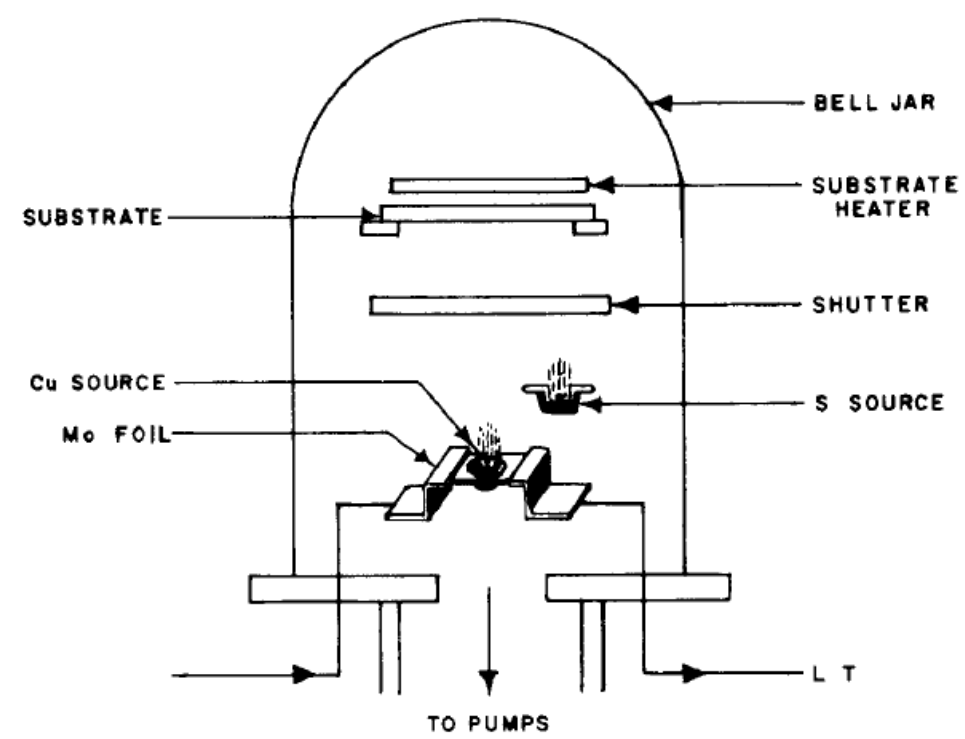

Fig (5) Bell jar balzer equipment 
of copper and sulphur starts. The shutter is then removed to ensure deposition of $\mathrm{Cu}_{2} \mathrm{~S}$ on the substrate. The substrates are maintained at room temperatures for $15 \mathrm{~min}$. the sample tested using pico ampere meter Khithley 6487 to measure the I-V characteristic.

\section{Results and discussion}

The I-V characteristic of the $\mathrm{Cu}_{2} \mathrm{~S} / \mathrm{Cu}$ structure (sample1) is shown in fig.(6). A negative voltage is applied to the $\mathrm{Cu}$ electrode with respect to $\mathrm{Al}$ electrode, it is clear that the sample has a small memory effect noticed in forward direction characteristics. The behavior characteristics are looking like linear resistor when the thickness is about $1000 \mathrm{~A}^{\circ}$. Fig.(7) shows the I-V characteristics of the $\mathrm{Cu}_{2} \mathrm{~S} / \mathrm{Cu}$ structure with $700 \mathrm{~A}^{\circ}$ thickness. The memory effect is increased in forward and reverse direction because the $\mathrm{Cu}$ filament bridge construct quickly and the cell transfer from OFF state to $\mathrm{ON}$ in wide current range. Both samples also tested in AC triangular voltage $(1 \mathrm{kHz})$ source to insure positive and negative voltage sweep, the two characteristic is shown in fig. (8\&9).

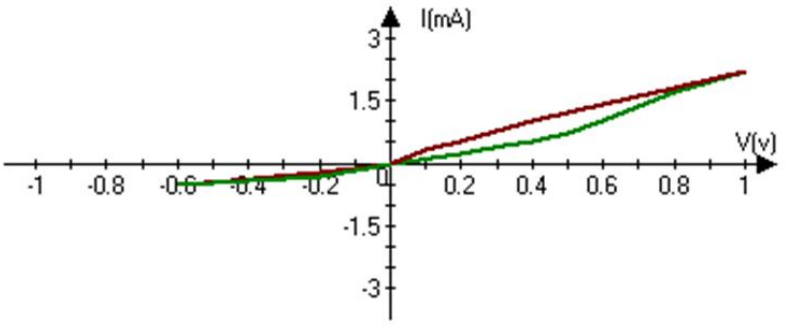

Fig.(6) I-V characteristic of $\mathrm{Cu}_{2} \mathrm{~S} / \mathrm{Cu}$ structure structure with $\mathrm{Cu}_{2} \mathrm{~S}$ thickness of $1000 \mathrm{~A}^{\circ}$

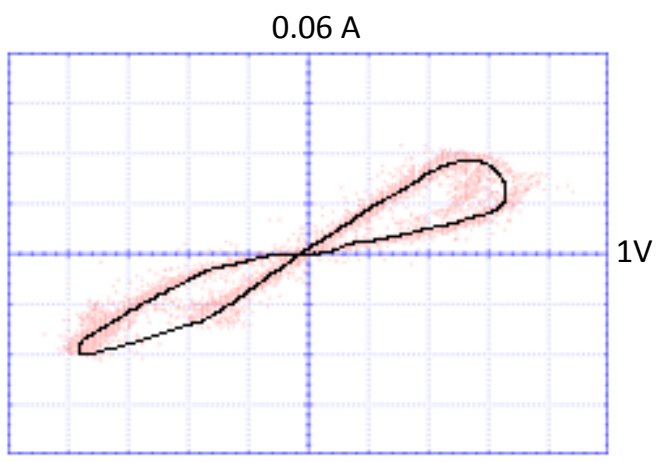

Fig.(8) I-V characteristic of $\mathrm{Cu}_{2} \mathrm{~S} / \mathrm{Cu}$ structure with triangular voltage source $(1 \mathrm{kHz}) \mathrm{Cu}_{2} \mathrm{~S}$ thickness $=1000 \mathrm{~A}^{\circ}$

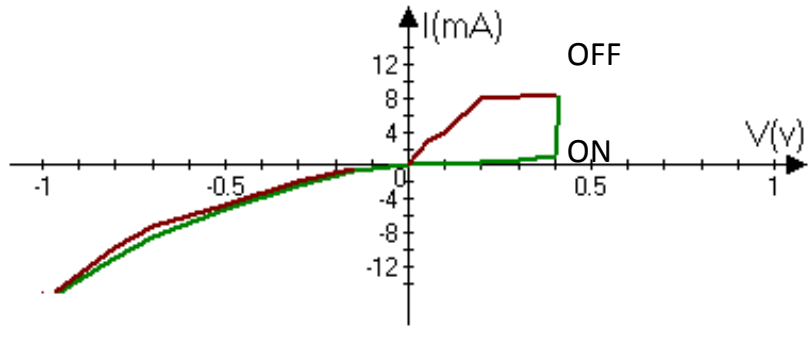

Fig.(7) I-V characteristic of $\mathrm{Cu}_{2} \mathrm{~S} / \mathrm{Cu}$ with $\mathrm{Cu}_{2} \mathrm{~S}$ thickness of $700^{\circ}$

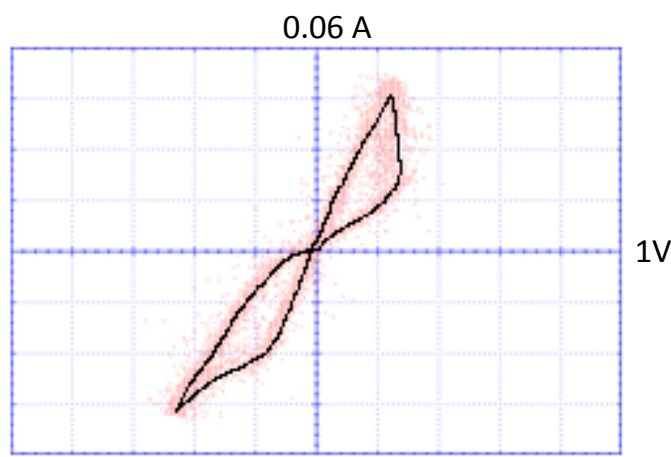

Fig.(9) I-V characteristic of $\mathrm{Cu}_{2} \mathrm{~S} / \mathrm{Cu}$ structure with triangular voltage source $(1 \mathrm{kHz}) \mathrm{Cu}_{2} \mathrm{~S}$ thickness $=700 \mathrm{~A}^{\circ}$

Fig. (10) and fig.(11) shows the DC and AC characteristics respectively of the $\mathrm{Cu}_{2} \mathrm{~S} / \mathrm{Cu}$ structure with a thickness of $400 \mathrm{~A}^{\circ}$. The memory effect is increased clearly and the $\mathrm{ON}$ resistance is measured and found to be $(10 \Omega)$, while the OFF resistance is more than $(100 \mathrm{k} \Omega)$. 


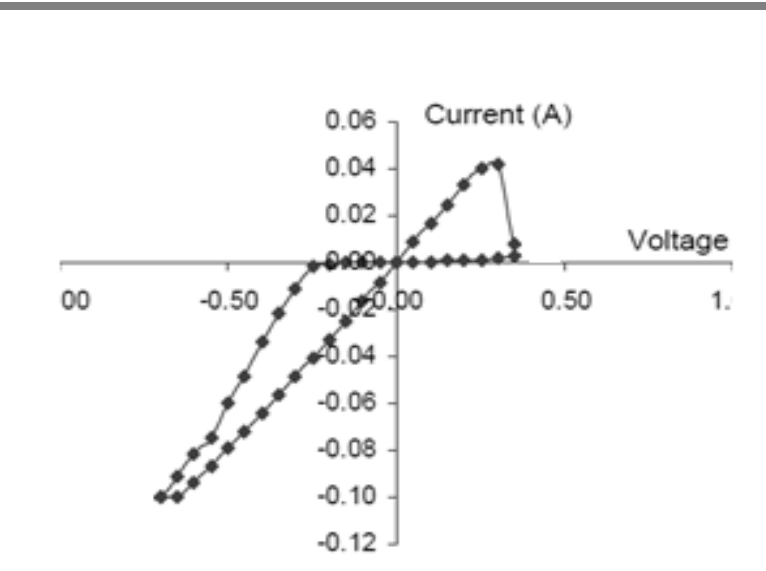

Fig.(10) Dc characteristic of $\mathrm{Cu}_{2} \mathrm{~S} / \mathrm{Cu}$ with with Thickness $=400 \mathrm{~A}^{\circ}$

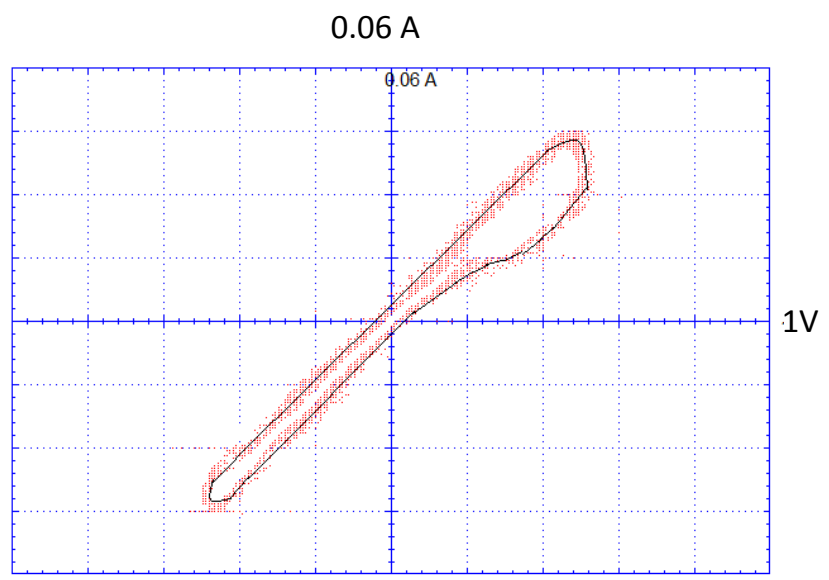

Fig.(11) Dc characteristic of $\mathrm{Cu}_{2} \mathrm{~S} / \mathrm{Cu}$ with Thickness $=400 \mathrm{~A}^{\circ}$

The last results prove the validity of using the $\mathrm{Cu}_{2} \mathrm{~S} / \mathrm{Cu}$ structure as high speed and low power memory cell, the low voltage swing of the cell between the ON and OFF state make these cell structures an attractive one because the transition between one and zero will take very short time compared to all other cell (very high speed logic).

\section{Conclusions}

The characteristic results obtained from experimental samples shows the conductive bridging memory cell (CBRM) is an attractive memory technology that offers simple integration and scalable operational condition. The fabricated $\mathrm{Cu}_{2} \mathrm{~S} / \mathrm{Cu}$ structure memory cell shows an ON resistance of about $10 \Omega$ and an OFF resistance of about $100 \mathrm{k} \Omega$ which make this structure as a candidate future memory cell with high speed and low power consumption.

\section{References}

1. Michael N. Kozicki, Chakravarthy Gopalan," Non-Volatile Memory Based on Solid Electrolytes," Center for Solid State Electronics Research Arizona State University.07803-8726-0/1/04/\$20.00@2004 IEEE

2.Massood Tabib-Azar, and Yan Xie,"Non-Volatile Solid-Electrolyte Memory Devices: Electronic versus Optical Latent Image Formation in Silver Halides," Case Western Reserve University Cleveland, Ohio 44106.ECS-Trans.3,28 2006

3. Chakravarthy Gopalan, Yi Ma, Tony Gallo," Demonstration of Conductive Bridging Random Access Memory (CBRAM) in Logic CMOS Process," 978-1-4244-6721$1 / 10 / \$ 26.00$ @2010 IEEE.

4. Naoki Banno, Toshitsugu Sakamoto," Diffusivity of Cu Ions in Solid Electrolyte and Its Effect on the Performance of Nanometer-Scale Switch," IEEE TRANSACTIONS ON ELECTRON DEVICES, VOL. 55, NO. 11, NOVEMBER 2008.

5. Yoshinao Okajima, Yasushi Shibuta," Numerical Simulation of Switching Behavior in Cu/Cu2S Nanometer-Scale Switch," Applied Physics Express 3 (2010) 065202.

6. LIANG YOU," Copper Sulfide Solid State Electrolytic Memory Devices”, thesis 2007

The work was carried out at the college of Engineering. University of Mosul 